\title{
Dietary fiber and grain consumption in relation to head and neck cancer in the NIH-AARP Diet and Health Study
}

\author{
Tram Kim Lam ${ }^{1,2}$, Amanda J Cross ${ }^{3}$, Neal Freedman ${ }^{3}$, Yikyung Park ${ }^{3}$, Albert R \\ Hollenbeck $^{4}$, Arthur Schatzkin ${ }^{3}$, and Christian Abnet ${ }^{3}$
}

${ }^{1}$ Genetics Epidemiology Branch, Division of Cancer, Epidemiology, and Genetics (DCEG), National Cancer Institute ( $\mathrm{NCl}$ ), National Institutes of Health $(\mathrm{NIH})$, Rockville, Maryland ${ }^{2}$ Cancer Prevention Fellowship Program, Office of Directors, $\mathrm{NCl}, \mathrm{NIH}$, Rockville, Maryland ${ }^{3} \mathrm{Nutritional}$ Epidemiology Branch, DCEG, NCI, NIH, Rockville, Maryland ${ }^{4}$ AARP, Washington, D.C.

\begin{abstract}
Background-Dietary fiber and grain consumption may reduce the risk of head and neck cancer; however, the epidemiological evidence is limited. We investigated this relationship in the National Institutes of Health (NIH)-AARP Diet and Health Study.

Methods-Cox proportional hazards models were used to calculate multivariable hazard ratios (HR) and 95\% confidence intervals (CI) to investigate dietary fiber and grain intake in relation to head and neck cancer.

Results-During approximately 11 years of follow-up, 1,867 (401 women/1,466 men) cases of head and neck cancer were diagnosed. Our data indicated that the relationship between fiber and grain intake and head and neck cancer is modified by sex ( $p$-interactions $<0.001$ and 0.001 , respectively). Women with higher intake of total fiber and total grains had a lower risk of head and neck cancer $\left(\mathrm{HR}_{10 \mathrm{~g} / \mathrm{day}}=0.77,95 \% \mathrm{CI}=0.64-0.93 ; \mathrm{HR}_{\text {serving } / 1000 \mathrm{kcal}}=0.89,95 \% \mathrm{CI}=0.80-0.99\right.$, respectively); this inverse relation was consistent across subtypes of fiber and grains. Conversely in men, the inverse associations were weaker and nonsignificant.
\end{abstract}

Conclusions-In the largest prospective cohort study to investigate this relation to date, intake of total fiber and grain foods was inversely associated with head and neck cancer incidence among women, but not men.

\section{Keywords}

diet; fiber; grains; head and neck cancer; prospective study

\section{Introduction}

Head and neck cancer encompasses those in the oral cavity, oropharynx, hypopharynx, and larynx [1]; collectively, they represent the sixth most common cancer worldwide, with an annual incidence of approximately 400,000 cases, of which two-thirds occur in developing countries [2]. In the United States, head and neck cancer accounts for approximately $3.2 \%$ of all new cancers and $2.0 \%$ of all cancer deaths [3]. Across countries and subsites, the incidence of head and neck cancer in men exceeds that of women by a factor of 3 to 10 .

Corresponding author: Dr. Tram Kim Lam, Genetics Epidemiology Branch, Division of Cancer Epidemiology, and Genetics, National Cancer Institute, National Institutes of Health, Rockville, Maryland 20852. Telephone: 301-402-9847. lamt@mail.nih.gov. 
Alcohol consumption and tobacco smoking are established risk factors for head and neck cancer [4], while diet may offer protection against this malignancy [4]. Specifically, fruit and vegetable intake was inversely associated with head and neck cancer in several prospective cohort studies[5-9], including the current one [9]. In reviewing the body of epidemiological evidence, the World Cancer Research Fund and the American Institute for Cancer Research concluded that intakes of fruit and non-starchy vegetables probably protect against cancers of the mouth, pharynx, and larynx [10].

Fruits and vegetables contain several potential anticarcinogens, including vitamin C, carotenoids/beta-carotene, and dietary fiber [11]. While a number of investigations [12, 13] have examined vitamin $\mathrm{C}$ and beta-carotene in relation to head and neck cancer, only a few studies have investigated fiber. Most previous studies of dietary fiber [14, 15] or fiber-rich whole grains [16-23] and cancer of the head and neck had a case-control design, vulnerable to methodological limitations including recall and selection bias. The few prospective studies [5-7] did not examine the risks by fiber subtypes, food source, or head and neck subsites; furthermore, case numbers were small. Therefore, we investigated the role of dietary fiber, total grain, and respective subtypes in relation to head and neck cancer in a large prospective cohort study by anatomic subsites and stratified by sex.

\section{Material and Methods}

\section{Study population}

The National Institutes of Health (NIH)-AARP Diet and Health Study has been described previously [24]. Briefly, the study recruited men and women by mailing questionnaires to 3.5 million AARP members aged 50-71 years old from six US states (California, Florida, Louisiana, New Jersey, North Carolina, and Pennsylvania) and 2 metropolitan areas (Atlanta, GA and Detroit, MI). Of the 566,402 individuals who returned satisfactorily completed questionnaires and consented to be in the study between 1995 to 1996, we excluded those who had previous cancer at baseline $(n=51,234)$, proxy respondents $(n=15,760)$, and those with box-cox log transformed total energy and total dietary fiber intake of more than two interquartile ranges from the median $(n=4,417)$. The analytical cohort comprised of 494,991 participants (295,312 men and 199,679 women).

\section{Case ascertainment}

We identified cancer cases through linkage with 10 state cancer registry databases that included the 8 original states and 2 additional states (Arizona, and Texas) that participants tended to move to during follow-up. Cancers were identified by anatomic site and histologic code of the International Classification of Disease for Oncology (ICD-O, third edition) [25]. Cases were restricted to squamous cell carcinomas. As previously described [26], the total head and neck cancer category included cancers of the oral cavity, oro-hypopharynx, larynx, as well as those overlapping these regions.

\section{Dietary assessment}

At baseline, we assessed diet with a self-administered 124-item food-frequency questionnaire (FFQ) that asked about the usual frequency of intake and portion size over the last 12 months, using 10 predefined frequency categories ranging from "never" to " $6+$ times per day" for beverages, from "never" to " $2+$ times per day" for solid foods, and 3 categories of portion size. The food items, portion sizes, and nutrient database were based on the method developed by Subar et al [27] using the US Department of Agriculture's (USDA) 1994-1996 Continuing Survey of Food Intakes by Individuals [28]. The nutrient database for dietary fiber was informed by the Association of Official Analytical Chemists method [29]. Over 100 food items contributed to the derivation of total grains, whole grains, and refined 
grains. The estimates for whole grains and refined grains were derived using the approach by the MyPyramid equivalent database. This approach assigned a relative proportion of whole grains and refined grains components to each food items depended on sex-specific portion size. A recipe file was used to disaggregate food mixtures into their component ingredients and assigns them to food groups. For analysis, portion sizes of total grains, whole grains, and refined grains, were defined using USDA cup equivalents, e.g. 1 slice of whole grain bread, 1 cup of ready-to-eat whole grain cereal, or $1 / 2$ cup of cooked whole grain [30].

The FFQ was validated using two nonconsecutive 24-hr dietary recalls in 1,953 participants. The energy-adjusted Pearson correlation coefficients for dietary fiber intake assessed by FFQ and two 24-hour recalls was 0.72 in men and 0.66 in women [31].

\section{Statistical analysis}

We used multivariate Cox proportional hazards regression models, after verifying that the proportional hazards assumption was met by modeling the cross-products of time and dietary fiber intake, to estimate hazard ratios (HRs) and 95\% confidence intervals (CIs) within sex-specific quintiles of intake. Person-years of follow-up time were calculated from the date of the baseline questionnaire until the date of cancer diagnosis, death, movement out of the registry areas, or end of follow-up (December $31^{\text {st }}$, 2006), whichever occurred first. Follow-up time was used as the underlying time metric. Linear trend tests across increasing categories of intake were conducted by assigning participants the median intake for their categories and entering that term as a continuous variable in the regression model.

Dietary fiber intake was adjusted for total energy intake using the residual method [32] while intake of total grains was energy adjusted by the nutrient density method, in which daily intake was expressed as grams per $1000 \mathrm{kcal}$. All models were adjusted for age (continuous), sex, education ( $<$ high school education, completion of high school, some posthigh school training, completion of college and completion of graduate school), body mass index (BMI; $<18.5,18.5$ to $<25,25$ to $<30,30$ to $<35$, and $\geq 35 \mathrm{~kg} / \mathrm{m}^{2}$ ), alcohol intake ( 0 , $>0-1,1-3$, and $>3$ drinks/day), smoking dose (never cigarette smoker, quit $\leq 1 \mathrm{pack} /$ day, quit $>1$ pack/day, currently smoking $\leq 1 \mathrm{pack} /$ day, and currently smoking $>1$ pack/day), vigorous physical activity (never, rarely, 1-3 times/month, 1-2 times/week, 3-4 times/week, 5+ times/ week), intake of red meat (quintiles), and total energy (continuous). Further adjustment for intake of fruit and vegetables, vitamin $\mathrm{C}$, folate, beta-carotene, or physical activity at work did not materially alter the results and were not included in the final models.

All analyses were performed stratified by sex. Smoking-stratified models were adjusted for smoking dose and years since smoking cessation where appropriate. To test for interactions, we multiplied the continuous fiber and grain variables by the stratifying variables (sex, smoking status, alcohol consumption) and calculated $p$-interaction using the likelihood ratio test (lrt) with the appropriate degrees of freedom. All analyses were performed using SAS version 9.1. An alpha level of less than 0.05 was considered statistically significant and all tests were two-sided.

\section{Results}

During up to 11 years of follow-up, we identified 1,867 cases of head and neck cancer (779 oral cavity, 337 oro-hypopharynx, 622 larynx, and 129 overlapping sites). Men and women reported similar intakes of total fiber and total grains. Men and women in the highest, compared to lowest, quintile of dietary fiber or total grain intake were older, more educated, and were more physically active; furthermore, they tended to have a lower BMI, consumed less alcohol, and less red meat (Table 1). Women in the highest quintile of total fiber and 
total grains tended to be never smokers, whereas men were more likely to be former smokers. Dietary fiber and subtypes were not highly correlated with total grain, whole grains, and refined grains (Pearson correlation coefficients <0.40).

We found that sex significantly modified the relation between head and neck cancer and intakes of total fiber ( $p$-interaction $<0.001)$, total grains $(p$-interaction $=0.001)$, and subtypes of fiber ( $p$-interactions $<0.05$ ); therefore, we presented sex-stratified estimates throughout. Total dietary fiber and grains were inversely associated with head and neck cancers in women; these associations were evident on the continuous scale (total fiber per $10 \mathrm{~g} / \mathrm{day}$ increase: $\mathrm{HR}=0.77,95 \% \mathrm{CI}=0.64-0.93$; total grains per serving/1,000 kcals: $\mathrm{HR}=0.89$, $95 \% \mathrm{CI}=0.80-0.99)$ and when comparing the highest to the lowest quintile of intake $\left(\mathrm{HR}_{\mathrm{Q} 5 \mathrm{vQ} 1}=0.61,95 \% \mathrm{CI}=0.42-0.89, p\right.$-trend $0.002 ; \mathrm{HR}_{\mathrm{Q} 5 \mathrm{vs} 1}=0.73,95 \% \mathrm{CI}=$ $0.53-1.02, p$-trend $=0.040$, respectively, Table 2$)$. The inverse association in women was consistent across subtypes of fiber and grains, including whole and refined grains (Table 2) and insoluble and soluble fiber (data not shown); but we did not observe significant dosedependent trends for fiber from beans $(p$-trend $=0.571)$.

In men, there was borderline statistically significant association for total fiber and total grains and head and neck cancer on the continuous scale (Table 2); we observed a statistically significant inverse association for fiber from fruits $\left(\mathrm{HR}_{\text {per gram } / \text { day }}=0.89 ; 95 \%\right.$ $\mathrm{CI}=0.81-0.97 ; \mathrm{HR}_{\mathrm{Q} 5 \mathrm{vs} 1}=0.83,95 \% \mathrm{CI}=0.69-0.99, p$-trend $=0.077$ ) and beans $\left(\mathrm{HR}_{\text {per gram } / \text { day }}=0.87 ; 95 \% \mathrm{CI}=0.78-0.97 ; \mathrm{HR}_{\mathrm{Q} 5 \mathrm{vs} 1}=0.82,95 \% \mathrm{CI}=0.69-0.96, p\right.$-trend $=0.012$ ). When examined by anatomic subsites, similar results for intakes of total fiber and total grains were observed, but they did not reach statistical significance (Table 3).

Regardless of sex, there was no effect modification by smoking status (Table 4). We observed statistically significant inverse association with higher intake of total grains for ever drinkers among men, but not for men who did not consume alcohol (Table 4, $p$ interaction $=0.011)$. No differential effect was observed in this group for total fiber intake. In women, no effect modification was observed for both food groups by alcohol consumption. We also explored effect modification by healthy lifestyle through stratified analyses by levels of physical activity, BMI, and education. We observed no evidence of effect modification by these variables (data not shown).

\section{Discussion}

In this prospective cohort study, we found an inverse association between dietary fiber and total grain intake and cancer of the head and neck in women; inverse associations persisted across different subgroups of fiber and grains, including whole and refined grains, and did not differ by subsites. In contrast, the associations were weaker, with borderline statistical significance, in men. Our analyses suggest that the benefit conferred by higher intakes of fiber and total grains may differ by sex.

Three previous prospective studies published on dietary fiber and grain intake in relation to upper aerodigestive tract cancer, which included subsites of head and neck cancer [5-7]. These studies were small (number of cases <95) and reported inconsistent results; furthermore, none comprehensively assessed fiber intake. Cohorts of Japanese [5] and Norwegian [6] men found inverse associations between consumption of bread and upper aerodigestive tract cancers $(\mathrm{HR}=0.80 ; 95 \% \mathrm{CI}=0.41-1.56$ and $\mathrm{HR}=0.20 ; 95 \% \mathrm{CI}=$ 0.1-0.5, respectively). In the Iowa Women's Health Study, inverse associations were observed for whole grains for both oral/pharyngeal cancers $(n=53, H R=0.47)$ and laryngeal cancer $(\mathrm{n}=21, \mathrm{HR}=0.44)$, whereas total fiber consumption was inversely associated with oral/pharyngeal $(H R=0.49)$ but not laryngeal cancer $(H R=1.82)$; the 
authors did not conduct statistical testing due to small numbers [7], Likewise, the epidemiological evidence from case-control studies on dietary fiber and grain intake is inconsistent [13]. Our findings showing an inverse association between fiber intake and head and neck cancer were similar to some case-control studies [14, 19, 33, 34], but not all [35].

The precise biological mechanism by which dietary fiber and grains might affect head and neck cancer risk is unknown: however, several biological reasons are plausible. Both dietary fiber and grains possess anticarcinogenic properties, which may directly or indirectly confer the protection observed. Dietary fiber scavenges nitrite, a precursor for carcinogenic nitrosoamines [36]. Nitrosoamines are possible risk factors for head and neck cancer [4]. Whole grains are grains in their original form contain three parts: the bran, the germ, and the endosperm [37]. Whole grains are rich in fiber, phytochemicals, antioxidants, and phytoestrogens, and lignans [37-39]. These constituents have been demonstrated to modify cancer risks, including head and neck cancer [4, 20]. Compared to whole grains, refined grains are nutritionally inferior because the milling process substantially reduced the nutrient contents of grains by removing the bran and germ-leaving a largely starchy endosperm. Our finding that refined grains also conferred protection against head and neck cancer does not support the hypothesis that starchy refined grains are risk factors for cancers $[14,40]$. It may suggest that other constituents in the endosperm, perhaps residual resistant starch, may play a protective etiologic role. Refined grains are also enriched with B vitamins (riboflavin, niacin, thiamin and iron) [41]. Nevertheless, it is speculative at best to attribute any of these constituents to the protection observed for refined grains in our study and additional research is warranted.

Our results may also be partly attributed to nutrients or micronutrients inherent in fruits and vegetables. Freedman et al previously showed that intake of fruits and vegetables was associated with a reduced risk of head and neck cancers in the same population [9]. In additional analyses, we further adjusted for intakes of fruits, vegetables, folate, betacarotene, and vitamin C. The observed inverse associations changed only slightly, suggesting that other dietary components found in fruits and vegetables do not fully explain the protective effect of dietary fiber and grains observed.

Alternatively, fiber and grain intake is associated with aspects of a healthy lifestyle, such as a lower propensity to smoke cigarettes and consume alcohol, lower BMI, and higher physical activity; as such unmeasured or poorly measured exposures could affect our results. Although we took great care to adjust for these confounders in our analyses, we cannot exclude the possibility of residual confounding affecting our results. In particular, cigarette smoking is a significant risk factor for head and neck cancer. Risk estimates for total fiber and total grains were attenuated in never smokers.

Despite similar reported median intakes of fiber and grains in the sex-specific quintiles, the observed sex-specific benefit merits further discussion. Head and neck cancer is considerably more common among men than women [4]. The sex-ratios range from 3 to 10 by anatomic subsite and can further vary within particular subsites, such as the larynx [2]. Tobacco exposure and alcohol consumption, both established risk factors for head and neck cancer, likely do not explain these differences as elevated incidence rates in men relative to women persisted in never smokers who did not drink alcohol in the NIH-AARP Diet and Health Study [26, 42]. The accumulating evidence led some investigators to postulate a possible role of estrogen and hormone-related factors in the etiology of head and neck cancer [43-46]. Recent findings from the NIH-AARP Diet and Health Study showed that menopausal hormone therapy (MHT) was inversely associated with incident squamous cell carcinomas, which included head and neck cancer [46]. Currently, it is unclear whether there is a role for dietary fiber and grains in hormone-related head and neck cancer, although 
dietary fiber and whole grains have been shown to reduce endogenous estrogen levels [47, 48]. In our analyses, additional adjustment for MHT and age at menopause did not affect the results.

The present study has several strengths. To our knowledge, it is the largest prospective cohort study to investigate the role of dietary fiber, grains, and their respective subtypes in relation to head and neck cancer, and first to report estimates across subsites within this group of malignancies. Furthermore, the relatively large number of head and neck cancers permitted assessment of sex-specific associations with dietary fiber and grain intake. The study benefits from a wide range of dietary fiber intake and detailed information on tobacco exposure and alcohol consumption, which allowed careful adjustment for these two important risk factors.

Limitations include the lack of information on human papillomavirus (HPV) infection, which is a risk factor for specific head and neck cancer subsites [49]. We investigated multiple subtypes of fiber, grains, and subsites of head and neck cancer; therefore, it is possible that our results might be due to chance. Additionally, we lack information on smoking duration and passive smoke exposure, which could possibly confound the observed relation. Although our study is the largest to date to examine the role of fiber and grains in relation to head and neck cancer, we are still limited by a modest numbers of cases, particularly for subgroup analyses.

In conclusion, total fiber and grains were inversely associated with head and neck cancers in this prospective cohort study. We observed a more pronounced benefit with intake of total fiber and grains among women compared to men. Our findings suggest a role of fiber and grains in the etiology of head and neck cancer.

\section{Acknowledgments}

This research was supported [in part] by the Intramural Research Program of the NIH, National Cancer Institute. Cancer incidence data from the Atlanta metropolitan area were collected by the Georgia Center for Cancer Statistics, Department of Epidemiology, Rollins School of Public Health, Emory University. Cancer incidence data from California were collected by the California Department of Health Services, Cancer Surveillance Section. Cancer incidence data from the Detroit metropolitan area were collected by the Michigan Cancer Surveillance Program, Community Health Administration, State of Michigan. The Florida cancer incidence data used in this report were collected by the Florida Cancer Data System (FCDC) under contract with the Florida Department of Health (FDOH). The views expressed herein are solely those of the authors and do not necessarily reflect those of the FCDC or FDOH. Cancer incidence data from Louisiana were collected by the Louisiana Tumor Registry, Louisiana State University Medical Center in New Orleans. Cancer incidence data from New Jersey were collected by the New Jersey State Cancer Registry, Cancer Epidemiology Services, New Jersey State Department of Health and Senior Services. Cancer incidence data from North Carolina were collected by the North Carolina Central Cancer Registry. Cancer incidence data from Pennsylvania were supplied by the Division of Health Statistics and Research, Pennsylvania Department of Health, Harrisburg, Pennsylvania. The Pennsylvania Department of Health specifically disclaims responsibility for any analyses, interpretations or conclusions. Cancer incidence data from Arizona were collected by the Arizona Cancer Registry, Division of Public Health Services, Arizona Department of Health Services. Cancer incidence data from Texas were collected by the Texas Cancer Registry, Cancer Epidemiology and Surveillance Branch, Texas Department of State Health Services.

We are indebted to the participants in the NIH-AARP Diet and Health Study for their outstanding cooperation. We also thank Sigurd Hermansen and Kerry Grace Morrissey from Westat for study outcomes ascertainment and management and Leslie Carroll at Information Management Services for data support and analysis.

\section{REFERENCES}

1. Evans, P Rhys; Montgomery, P.; Gullane, P. Principles and practice of head and neck oncology. Martin Dunitz; London: 2003.

2. Parkin DM, Bray F, Ferlay J, Pisani P. Global cancer statistics, 2002. CA Cancer J Clin. 2005; 55:74-108. [PubMed: 15761078] 
3. Jemal A, Siegel R, Ward E. Cancer statistics, 2009. CA Cancer J Clin. 2009; 59:225-49. [PubMed: 19474385]

4. Sturgis EM, Wei Q, Spitz MR. Descriptive epidemiology and risk factors for head and neck cancer. Semin Oncol. 2004; 31:726-33. [PubMed: 15599850]

5. Chyou PH, Nomura AM, Stemmermann GN. Diet, alcohol, smoking and cancer of the upper aerodigestive tract: a prospective study among Hawaii Japanese men. Int J Cancer. 1995; 60:61621. [PubMed: 7860134]

6. Kjaerheim K, Gaard M, Andersen A. The role of alcohol, tobacco, and dietary factors in upper aerogastric tract cancers: a prospective study of 10,900 Norwegian men. Cancer Causes Control. 1998; 9:99-108. [PubMed: 9486469]

7. Kasum CM, Jacobs DR Jr. Nicodemus K, Folsom AR. Dietary risk factors for upper aerodigestive tract cancers. Int J Cancer. 2002; 99:267-72. [PubMed: 11979443]

8. Boeing H, Dietrich T, Hoffmann K. Intake of fruits and vegetables and risk of cancer of the upper aero-digestive tract: the prospective EPIC-study. Cancer Causes Control. 2006; 17:957-69. [PubMed: 16841263]

9. Freedman ND, Park Y, Subar AF. Fruit and vegetable intake and head and neck cancer risk in a large United States prospective cohort study. Int J Cancer. 2007

10. World Cancer Research Fund/American Institute for Cancer Research. Food, Nutrition, Physical Activity, and the Prevention of cancer: a Global Perspective. AICR; Washington DC: 2007.

11. La Vecchia C, Tavani A. Fruit and vegetables, and human cancer. Eur J Cancer Prev. 1998; 7:3-8. [PubMed: 9511846]

12. Riboli E, Kaaks R, Esteve J. Nutrition and laryngeal cancer. Cancer Causes Control. 1996; 7:14756. [PubMed: 8850442]

13. Garavello W, Lucenteforte E, Bosetti C, La Vecchia C. The role of foods and nutrients on oral and pharyngeal cancer risk. Minerva Stomatol. 2009; 58:25-34. [PubMed: 19234434]

14. Levi F, Pasche C, Lucchini F. Refined and whole grain cereals and the risk of oral, oesophageal and laryngeal cancer. Eur J Clin Nutr. 2000; 54:487-9. [PubMed: 10878650]

15. Chatenoud L, Tavani A, La Vecchia C. Whole grain food intake and cancer risk. Int J Cancer. 1998; 77:24-8. [PubMed: 9639389]

16. McLaughlin JK, Gridley G, Block G. Dietary factors in oral and pharyngeal cancer. J Natl Cancer Inst. 1988; 80:1237-43. [PubMed: 3418729]

17. De Stefani E, Ronco A, Mendilaharsu M, Deneo-Pellegrini H. Diet and risk of cancer of the upper aerodigestive tract--II. Nutrients. Oral Oncol. 1999; 35:22-6.

18. Pelucchi C, Talamini R, Levi F. Fibre intake and laryngeal cancer risk. Ann Oncol. 2003; 14:1627. [PubMed: 12488309]

19. Soler M, Bosetti C, Franceschi S. Fiber intake and the risk of oral, pharyngeal and esophageal cancer. Int J Cancer. 2001; 91:283-7. [PubMed: 11169948]

20. Lucenteforte E, Garavello W, Bosetti C, La Vecchia C. Dietary factors and oral and pharyngeal cancer risk. Oral Oncol. 2009; 45:461-7. [PubMed: 18990606]

21. La Vecchia C, Chatenoud L, Negri E, Franceschi S. Session: whole cereal grains, fibre and human cancer wholegrain cereals and cancer in Italy. Proc Nutr Soc. 2003; 62:45-9. [PubMed: 12740056]

22. Chatenoud L, La Vecchia C, Franceschi S. Refined-cereal intake and risk of selected cancers in italy. Am J Clin Nutr. 1999; 70:1107-10. [PubMed: 10584057]

23. Franceschi S, Barra S, La Vecchia C. Risk factors for cancer of the tongue and the mouth. A casecontrol study from northern Italy. Cancer. 1992; 70:2227-33. [PubMed: 1394055]

24. Schatzkin A, Subar AF, Thompson FE. Design and serendipity in establishing a large cohort with wide dietary intake distributions : the National Institutes of Health-American Association of Retired Persons Diet and Health Study. Am J Epidemiol. 2001; 154:1119-25. [PubMed: 11744517]

25. Fritz, A. International Classification of Diseases for Oncology: ICD-O. World Health Organization; Geneva: 2000.

26. Freedman ND, Schatzkin A, Leitzmann MF, Hollenbeck AR, Abnet CC. Alcohol and head and neck cancer risk in a prospective study. Br J Cancer. 2007; 96:1469-74. [PubMed: 17387340] 
27. Subar AF, Midthune D, Kulldorff M. Evaluation of alternative approaches to assign nutrient values to food groups in food frequency questionnaires. Am J Epidemiol. 2000; 152:279-86. [PubMed: 10933275]

28. Tippett, K. Design and operation: the continuing survey of food intakes by individuals and diet and health knowledge survey, 1994-1996. continuing survey of food intakes by indivudals, nationwide food surveys. US Department of Argriculture, Agricultural Research Service; Washington, DC: 1997.

29. Prosky L, Asp NG, Furda I. Determination of total dietary fiber in foods and food products: collaborative study. J Assoc Off Anal Chem. 1985; 68:677-9. [PubMed: 2993226]

30. Friday, JE.; Bowman, SA. MyPyramid Equivalents Database for USDA Survey Food Codes, 1994-2002. 2006 ed. Community Nutrition Research Group; USDA, ARS: 2006.

31. Thompson FE, Kipnis V, Midthune D. Performance of a food-frequency questionnaire in the US NIH-AARP (National Institutes of Health-American Association of Retired Persons) Diet and Health Study. Public Health Nutr. 2008; 11:183-95. [PubMed: 17610761]

32. Willett W, Stampfer MJ. Total energy intake: implications for epidemiologic analyses. Am J Epidemiol. 1986; 124:17-27. [PubMed: 3521261]

33. Uzcudun AE, Retolaza IR, Fernandez PB. Nutrition and pharyngeal cancer: results from a casecontrol study in Spain. Head Neck. 2002; 24:830-40. [PubMed: 12211047]

34. Franceschi S, Bidoli E, Baron AE. Nutrition and cancer of the oral cavity and pharynx in north-east Italy. Int J Cancer. 1991; 47:20-5. [PubMed: 1985874]

35. De Stefani E, Deneo-Pellegrini H, Mendilaharsu M, Ronco A. Diet and risk of cancer of the upper aerodigestive tract--I. Foods. Oral Oncol. 1999; 35:17-21. [PubMed: 10211305]

36. Moller ME, Dahl R, Bockman OC. A possible role of the dietary fibre product, wheat bran, as a nitrite scavenger. Food Chem Toxicol. 1988; 26:841-5. [PubMed: 2851507]

37. Fardet A New hypotheses for the health-protective mechanisms of whole-grain cereals: what is beyond fibre? Nutr Res Rev. 23:65-134. [PubMed: 20565994]

38. Maras JE, Newby PK, Bakun PJ, Ferrucci L, Tucker KL. Whole grain intake: The Baltimore Longitudinal Study of Aging. J Food Compost Anal. 2009; 22:53-8. [PubMed: 20126297]

39. Slavin JL. Mechanisms for the impact of whole grain foods on cancer risk. J Am Coll Nutr. 2000; 19:300S-7S. [PubMed: 10875601]

40. Fernandez E, Gallus S, La Vecchia C. Nutrition and cancer risk: an overview. J Br Menopause Soc. 2006; 12:139-42. [PubMed: 17178013]

41. Slavin JL. Whole grains, refined grains and fortifed refined grains: What's the difference? Asia Pacific J Clin Nutr. 2000:S23-S7.

42. Freedman ND, Abnet CC, Leitzmann MF, Hollenbeck AR, Schatzkin A. Prospective investigation of the cigarette smoking-head and neck cancer association by sex. Cancer. 2007; 110:1593-601. [PubMed: 17724671]

43. Yoo HJ, Sepkovic DW, Bradlow HL. Estrogen metabolism as a risk factor for head and neck cancer. Otolaryngol Head Neck Surg. 2001; 124:241-7. [PubMed: 11240983]

44. Lukits J, Remenar E, Raso E. Molecular identification, expression and prognostic role of estrogenand progesterone receptors in head and neck cancer. Int J Oncol. 2007; 30:155-60. [PubMed: 17143524]

45. Ferguson BJ, Hudson WR, McCarty KS Jr. Sex steroid receptor distribution in the human larynx and laryngeal carcinoma. Arch Otolaryngol Head Neck Surg. 1987; 113:1311-5. [PubMed: 3314913]

46. Freedman ND, Lacey JV Jr. Hollenbeck AR. The association of menstrual and reproductive factors with upper gastrointestinal tract cancers in the NIH-AARP cohort. Cancer. 2007; 116:1572-81. [PubMed: 20186831]

47. Kuiper GG, Lemmen JG, Carlsson B. Interaction of estrogenic chemicals and phytoestrogens with estrogen receptor beta. Endocrinology. 1998; 139:4252-63. [PubMed: 9751507]

48. Adlercreutz H. Lignans and human health. Crit Rev Clin Lab Sci. 2007; 44:483-525. [PubMed: 17943494] 
49. Hennessey PT, Westra WH, Califano JA. Human papillomavirus and head and neck squamous cell carcinoma: recent evidence and clinical implications. J Dent Res. 2009; 88:300-6. [PubMed: 19407148] 


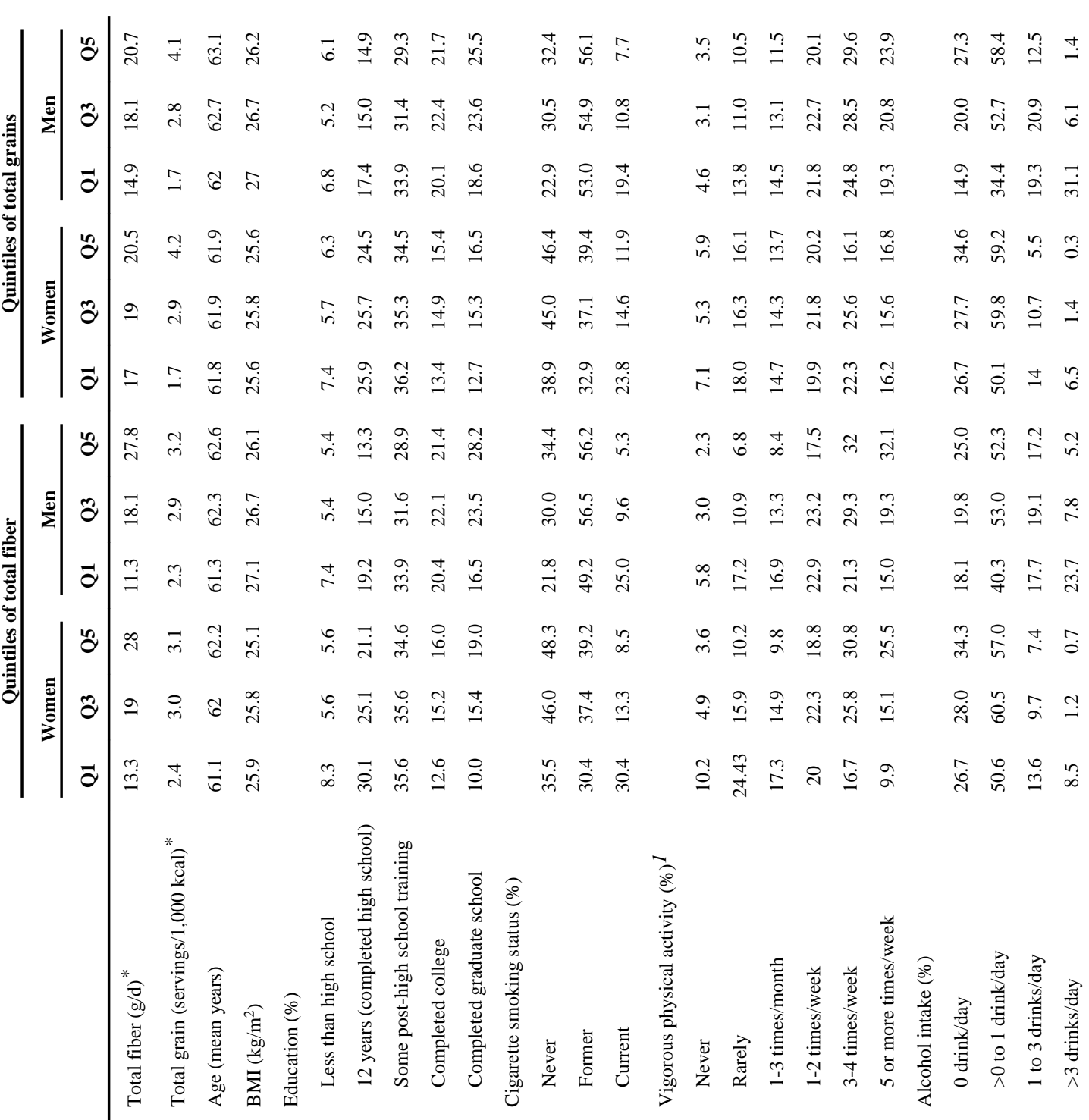




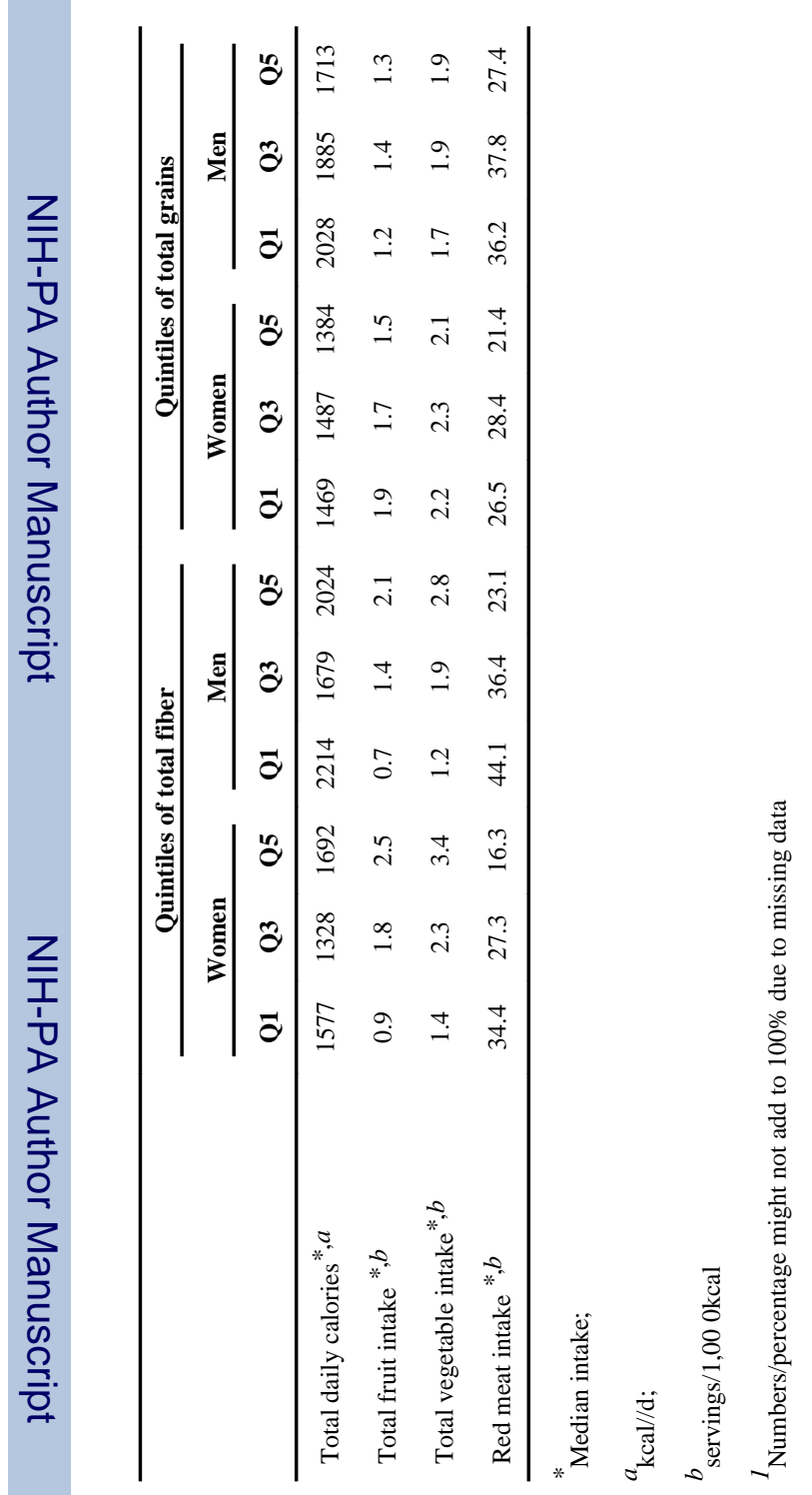

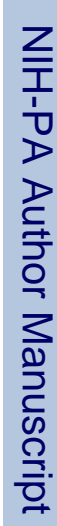




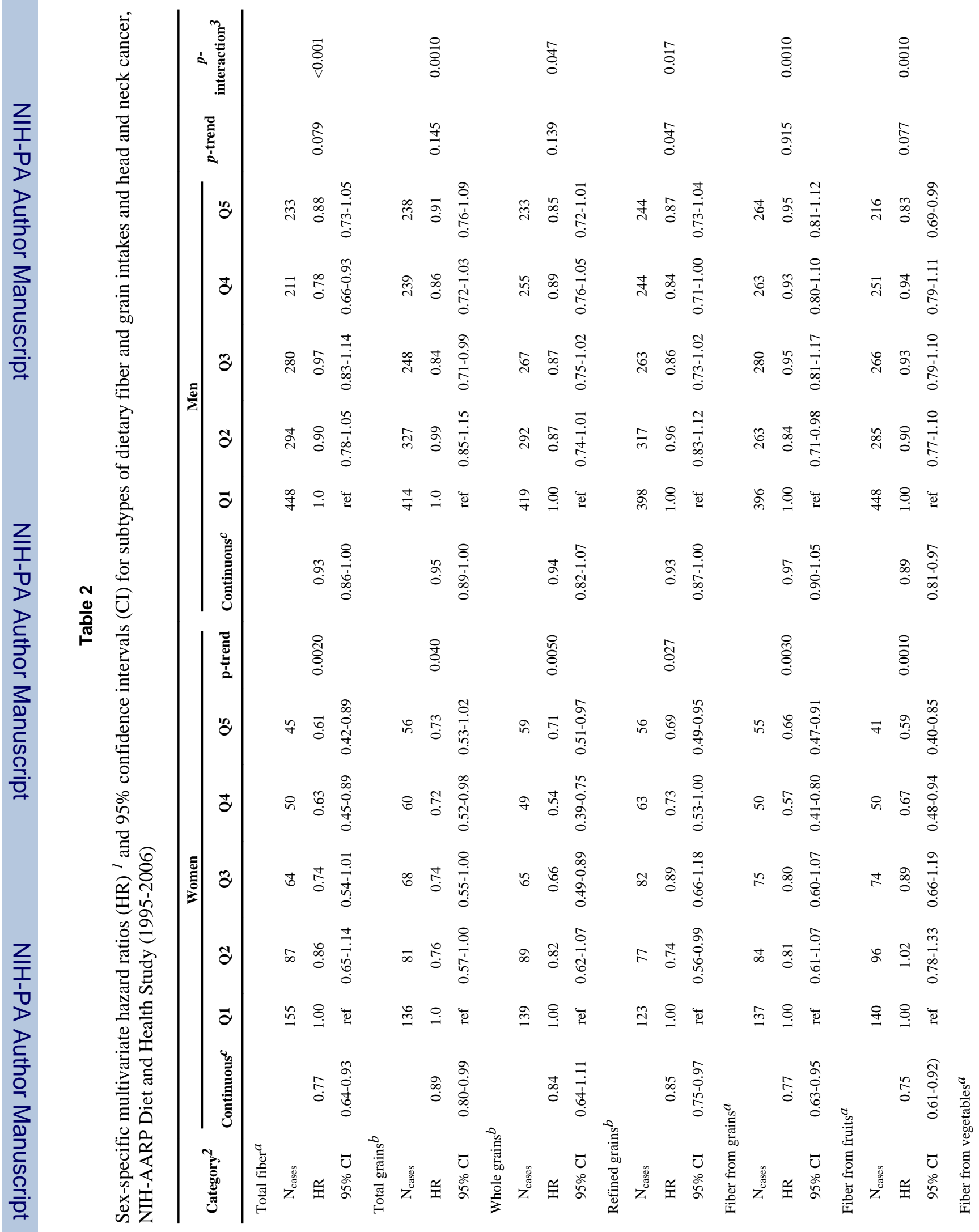




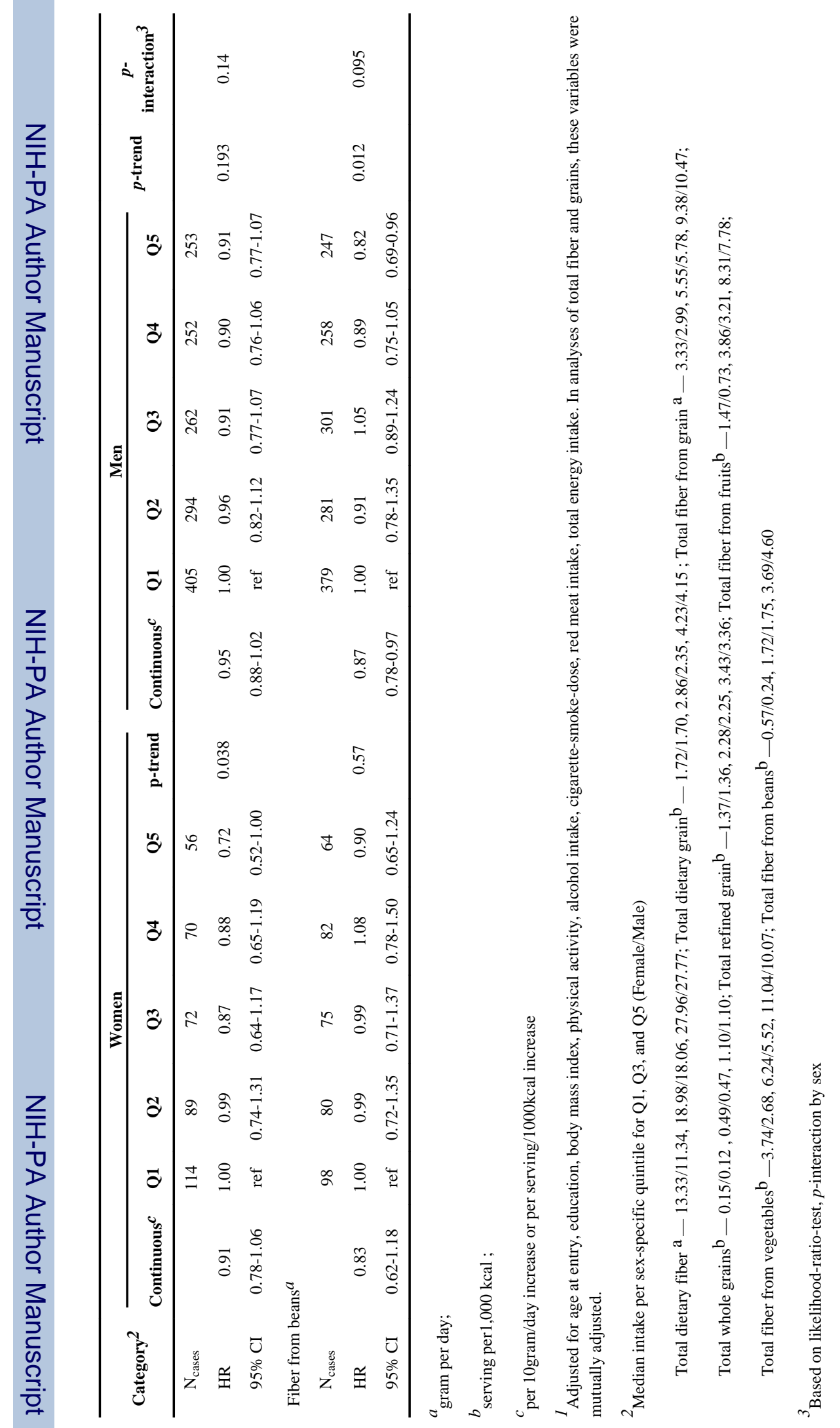




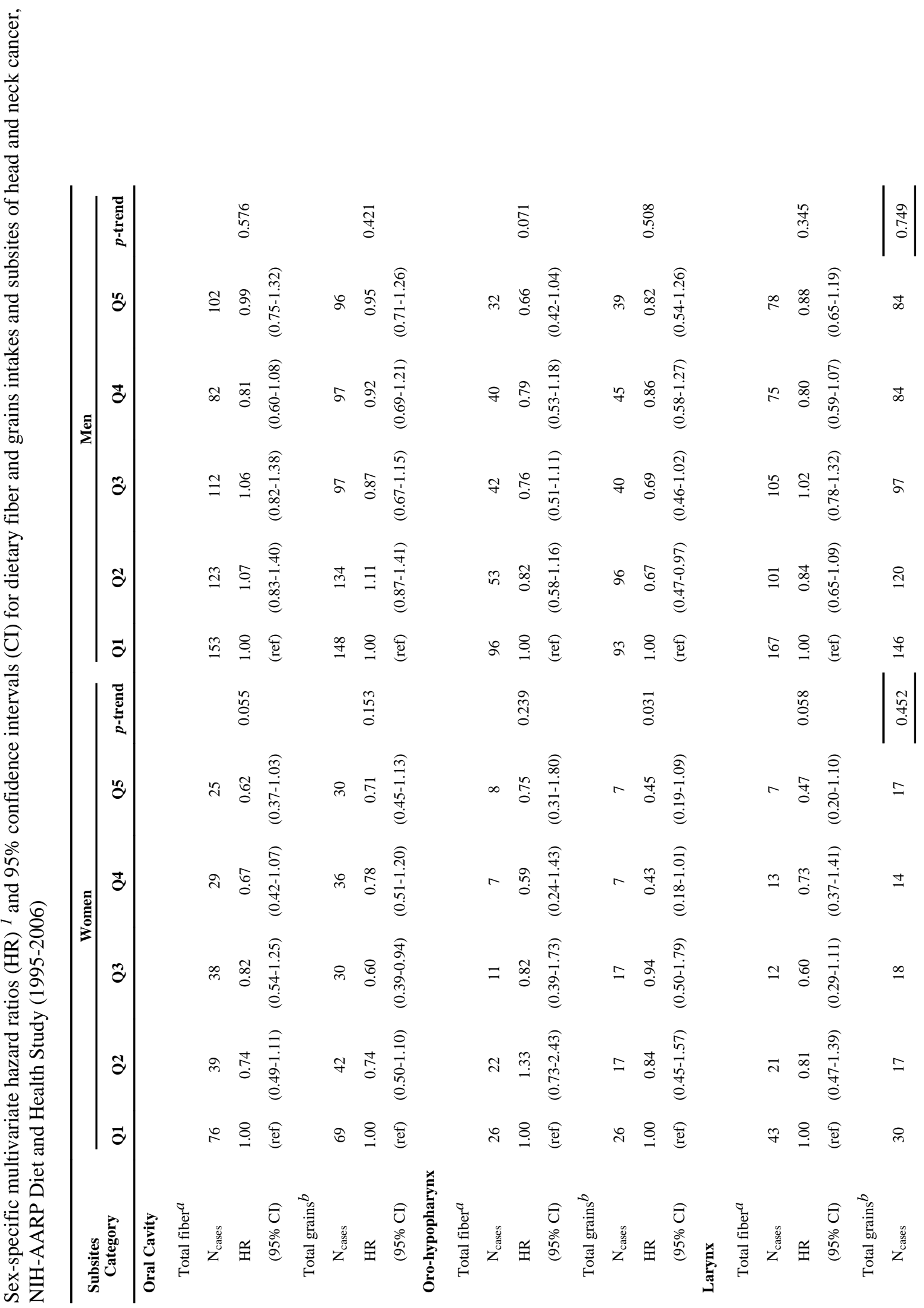




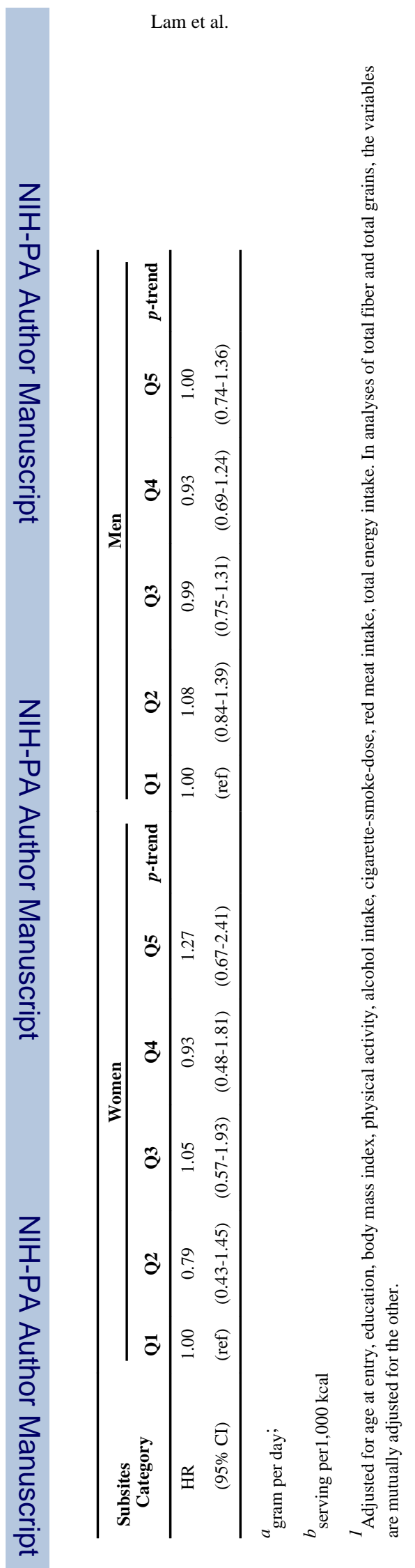

Page 15

Cancer Causes Control. Author manuscript; available in PMC 2012 October 1. 


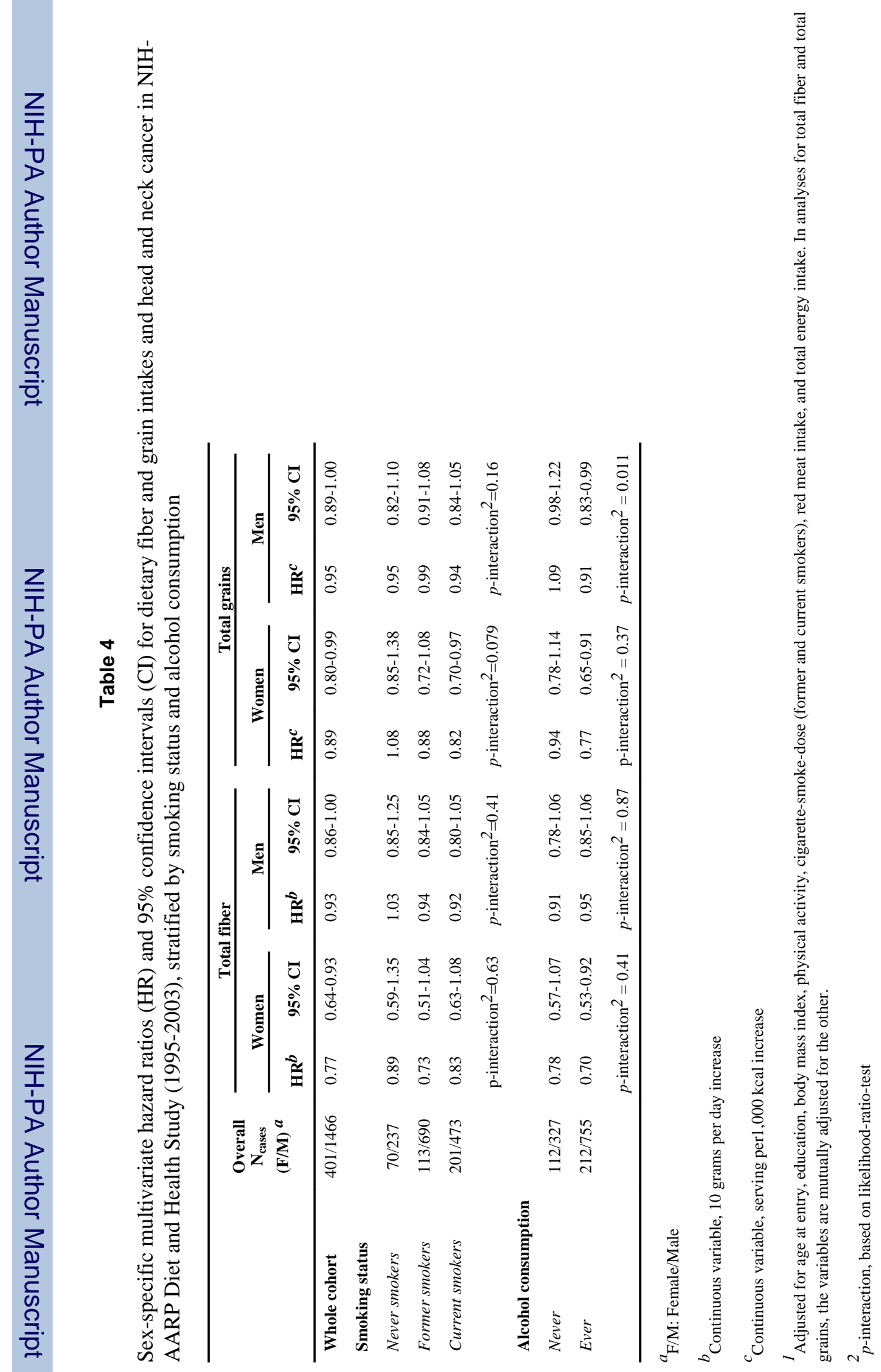

